\title{
Organic Radical-Assisted Electrochemical Exfoliation for the Scalable Production of High-Quality Graphene
}

\author{
Sheng Yang, ${ }^{\dagger}$ Sebastian Brüller, ${ }^{\dagger}$ Zhong-Shuai Wu, ${ }^{\dagger}$ Zhaoyang Liu, ${ }^{\dagger}$ Khaled Parvez, ${ }^{\dagger}$ Renhao Dong, ${ }^{\ddagger}$ \\ Fanny Richard, ${ }^{\S, \|}$ Paolo Samorì, ${ }^{\S, \|}$ Xinliang Feng, ${ }^{*}, \ddagger$ and Klaus Müllen ${ }^{*} \dagger$ \\ ${ }^{\dagger}$ Max-Planck-Institut für Polymerforschung, Ackermannweg 10, 55128 Mainz, Germany \\ ${ }^{\ddagger}$ Center for Advancing Electronics Dresden (CFAED) and Department of Chemistry and Food Chemistry, Technische Universität \\ Dresden, Mommsenstraße 4, 01062 Dresden, Germany \\ ${ }^{\S}$ ISIS, Université de Strasbourg, 8 Allée Gaspard Monge, 67083 Strasbourg, France

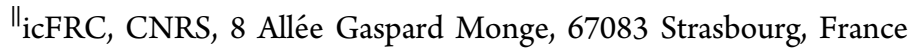

Supporting Information

\begin{abstract}
Despite the intensive research efforts devoted to graphene fabrication over the past decade, the production of high-quality graphene on a large scale, at an affordable cost, and in a reproducible manner still represents a great challenge. Here, we report a novel method based on the controlled electrochemical exfoliation of graphite in aqueous ammonium sulfate electrolyte to produce graphene in large quantities and with outstanding quality. Because the radicals (e.g., $\mathrm{HO}^{\bullet}$ ) generated from water electrolysis are responsible for defect formation on graphene during electrochemical exfoliation, a series of reducing agents as additives (e.g., (2,2,6,6-tetramethylpiperidin-1-yl)oxyl (TEMPO), ascorbic acid, and sodium borohydride) have been investigated to eliminate these radicals and thus control the exfoliation process. Remarkably, TEMPO-assisted exfoliation results in large graphene sheets $(5-10 \mu \mathrm{m}$ on average), which exhibit outstanding hole mobilities $\left(\sim 405 \mathrm{~cm}^{2} \mathrm{~V}^{-1} \mathrm{~s}^{-1}\right)$, very low Raman $I_{\mathrm{D}} / I_{\mathrm{G}}$ ratios (below 0.1 ), and extremely high carbon to oxygen (C/

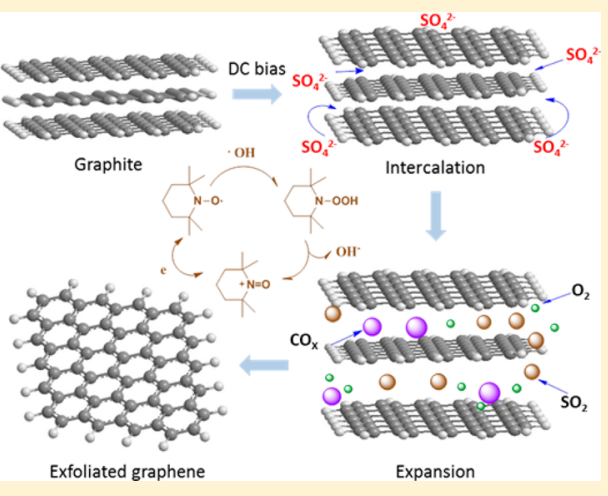
O) ratios ( 25.3). Moreover, the graphene ink prepared in dimethylformamide can exhibit concentrations as high as $6 \mathrm{mg} \mathrm{mL}^{-1}$, thus qualifying this material for intriguing applications such as transparent conductive films and flexible supercapacitors. In general, this robust method for electrochemical exfoliation of graphite offers great promise for the preparation of graphene that can be utilized in industrial applications to create integrated nanocomposites, conductive or mechanical additives, as well as energy storage and conversion devices.
\end{abstract}

\section{INTRODUCTION}

The exceptional electronic, thermal, optical, and mechanical properties of graphene render it a remarkable candidate for the next generation of electronic and optoelectronic devices. ${ }^{1}$ Consequently, techniques for the scalable production of highquality, solution-processable graphene are needed. Among the numerous protocols employed to date, the exfoliation of bulk graphite is most common for harvesting graphene sheets on a large scale because of its low process complexity and costs. Direct exfoliation in the solid state (e.g., scotch-tape cleavage, ${ }^{2}$ ball milling ${ }^{3,4}$ ) or in a liquid phase (e.g., liquid phase sonication, ${ }^{5-7}$ shear force exfoliation ${ }^{8}$ ), also known as physical exfoliation, provides feasible means for producing graphene with a low number of defects, although in an insufficient yield $(<5 \%)$ and/or with small flake sizes $(<1 \mu \mathrm{m})$. In comparison, chemical exfoliation, which generally relies on Hummers' method, offers a wide range of flexibility for the production of graphene oxide $(\mathrm{GO})$ and related materials because of the potential scalability, impressive conversion efficiency $(\sim 100 \%)$, and superior processability. Unfortunately, the unique physical properties of graphene are seriously compromised and cannot be sufficiently recovered, even upon reduction, because of the appreciable fraction of oxygen groups and defects that are left behind. These oxygen groups restrict its usage in fine applications. ${ }^{9,10}$

Electrochemical exfoliation has recently emerged as a promising strategy for producing graphene on an industrial scale with high efficiency, at low cost, and in an environmentally friendly manner. ${ }^{11}$ Either cathodic or anodic potentials are able to drive guest ions into graphitic layers, which promotes the structural deformation of a graphite working electrode. ${ }^{12,13}$ Cationic intercalation (mainly in organic electrolytes) does not involve oxidizing conditions and therefore avoids the decoration of the final products with oxygen containing groups. Unfortunately, in most cases, the produced graphene is in the form of a few layers, and its further isolation requires prolonged sonication $(>10 \mathrm{~h})$ or other

Received: August 25, 2015

Published: October 13, 2015 

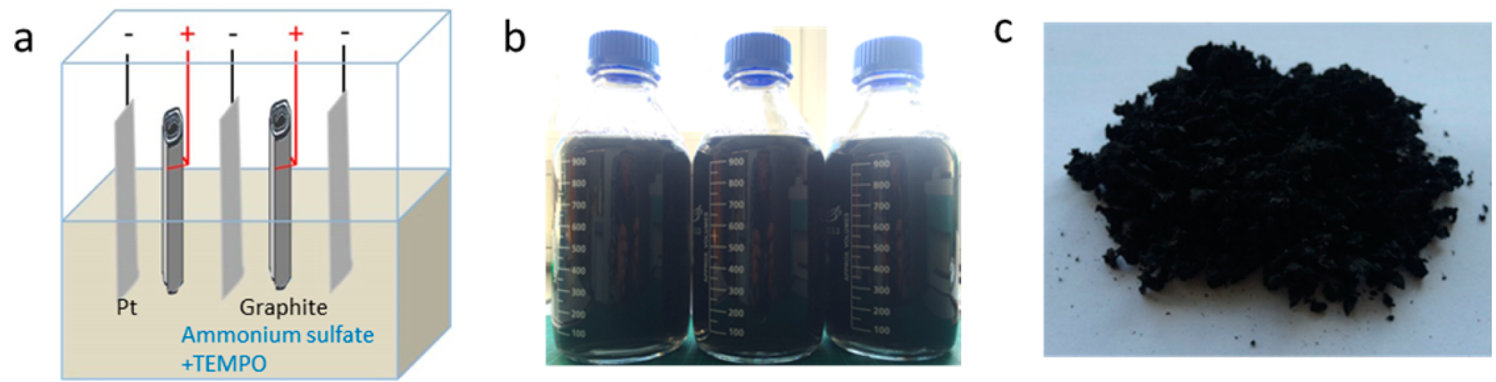

Figure 1. Electrochemical exfoliation of graphite: (a) schematic illustration of an electrochemical cell, (b) stable graphene-DMF dispersions prepared from radical-assisted electrochemical exfoliation, and (c) dried graphene powder $(\sim 15.1 \mathrm{~g})$.

multistep treatments (e.g., microwave irradiation). ${ }^{12,14-16}$ Anionic intercalation (primarily in aqueous electrolytes) is less time demanding and can take less than $1 \mathrm{~h}$. However, the graphene produced is generally decorated with functional oxygen groups that occur due to the positive potentials used, especially with acidic electrolytes (e.g., sulfuric acid ${ }^{17,18}$ ). It is noteworthy that the strong oxidation can be partially alleviated by using aqueous sulfonic salts as electrolytes. ${ }^{19}$ Nevertheless, the radicals (e.g., $\mathrm{HO}^{\bullet}$ ) generated from water electrolysis will unavoidably disrupt the graphitic structure during the exfoliation process. ${ }^{11,18,20,21}$ Therefore, it is highly desirable to eliminate these radicals to ultimately improve the quality of the graphene.

In this study, the electrochemical exfoliation of graphene is carried out in the presence of a series of antioxidants (such as ascorbic acid, gallic acid, hydrazine, sodium borohydride, hydrogen iodide, and (2,2,6,6-tetramethylpiperidin-1-yl)oxyl (TEMPO)) in a neutral aqueous electrolyte (ammonium sulfate) to suppress the formation of radicals from water electrolysis. Remarkably, using TEMPO, the electrochemically exfoliated graphene (EG) produced is of exceptionally high quality, and the process gives high exfoliation efficiencies. TEMPO is an inexpensive compound, and it has been widely used to terminate chain growth in controlled free radical polymerization. $^{22-24}$ Specifically, the produced EG exhibits large lateral sizes (ranging from 5 to $10 \mu \mathrm{m}$ ), outstanding hole mobilities $\left(\sim 405 \mathrm{~cm}^{2} \mathrm{~V}^{-1} \mathrm{~s}^{-1}\right)$, very low Raman $I_{\mathrm{D}} / I_{\mathrm{G}}$ ratios (below 0.1 ), and extremely high carbon to oxygen $(\mathrm{C} / \mathrm{O})$ ratios (25.3). Moreover, the throughput can be readily increased through continuous production $(\sim 15.1$ g per hour in laboratory tests). In addition, such high-quality EG still shows great processability in various solvents, such as $N, N$-dimethylforamide (DMF), to form concentrated stable dispersions $(6 \mathrm{mg}$ $\left.\mathrm{mL}^{-1}\right)$. This graphene ink allows for the fabrication of conductive films and supercapacitors. A $20 \mathrm{~nm}$-thick graphene film exhibits a sheet resistance as low as $3.91 \mathrm{k} \Omega \mathrm{sq}^{-1}$, decreasing further to $0.51 \mathrm{k} \Omega \mathrm{sq}^{-1}$ upon doping with $\mathrm{HNO}_{3}$. An assembled graphene paper supercapacitor demonstrates a high area capability of $11.5 \mathrm{mF} \mathrm{cm} \mathrm{cm}^{-2}$ (at a scan rate of $2 \mathrm{mV}$ $\mathrm{s}^{-1}$ ). The electrochemically exfoliated high-quality graphene will be useful in applications that involve hybrid composites, conductive or mechanical additives, and energy storage and conversion devices, among others.

\section{RESULTS AND DISCUSSION}

Electrochemical Exfoliation. Graphite exfoliation was conducted in a home-built setup that used rolled graphite foils as working electrodes and platinum foils as counter electrodes (Figure 1a). An aqueous solution containing ammonium sulfate with a range of reducing agents (e.g., ascorbic acid, gallic acid, hydrazine monohydrate, sodium borohydride $\left(\mathrm{NaBH}_{4}\right)$, hydrogen iodide, TEMPO; chemical structures shown in Figure S1) was tested as an electrolyte. Before exfoliation, the graphite foil was pretreated by alternately soaking it in liquid nitrogen and absolute ethanol. During this process, violent nitrogen evolution and ethanol solidification promoted the expansion of the graphite foils. The dilation was extremely rapid (within $10 \mathrm{~s}$ ) and yielded a drastic volume increase at the graphite boundary ( $\sim 10$ times) (Figure S2), which facilitated the expansion of the graphite layers, as did the following anion intercalation steps. When the graphite anodes were immersed in the electrolyte, by applying a static bias of $10 \mathrm{~V}$, they detached into small pieces in less than $10 \mathrm{~s}$, spreading on top of the electrolyte and/or on the bottom of the electrochemical cell. After filtration and copious washing, these exfoliated graphene sheets were collected and then dispersed in DMF via mild sonication. A stable dispersion with a concentration of $\sim 0.3 \mathrm{mg} \mathrm{mL}^{-1}$ was obtained that was stable for 2 weeks without apparent aggregation (Figure 1b). The total exfoliation yield was calculated using the mass ratio of dried graphene powder and the starting graphite precursor. Among the reductants, gallic acid and hydrogen iodide were not stable after turning on the electrical voltage. Hydrazine promoted exfoliation in very limited yield (less than $10 \mathrm{wt} \%$ ). The addition of ascorbic acid, sodium borohydride, or TEMPO into conventional ammonium sulfate electrolyte does not change the efficiency of graphite exfoliation. Especially, a high yield of $75 \mathrm{wt} \%$ has been achieved with the use of TEMPO. It is worth noting that to maintain a constant concentration of sodium borohydride, it should be added successively because its hydrolysis occurs spontaneously during the exfoliation process. Moreover, depending on the size of the graphite foil and the volume of the electrolyte, the throughput can be easily scaled up to tens of grams. For instance, a midsized electrochemical cell was tested in continuous exfoliation with two graphite foils (A4 size, $\sim 30 \mathrm{~cm} \times 20 \mathrm{~cm}$ ), which enabled the production of $\sim 15.1 \mathrm{~g}$ of graphene per hour (Figure 1c).

Morphological Elucidation. When a voltage was applied, the morphology of the graphite changed abruptly within a few seconds at both the surface and the boundaries (Figure S3); this behavior was independent of the type of reducing agents employed in the electrolyte. Typically, the as-received graphite foil possesses a smooth surface and a clean edge. After $5 \mathrm{~s}$ of exfoliation, cracks, bulges, and crumbles were observed both on the surface and at the boundaries. After $10 \mathrm{~s}$, the surface exhibited more irregular and rougher microstructures, including a network of ripples. The visible gas evolution led to the swelling of the graphite layers, which caused an obvious 
expansion at the edges. After $30 \mathrm{~s}$, the surface was altered to a curled morphology that consisted of thin, wrinkled, tissue-like structures. The edge of the graphite foil expanded to a size almost 10 times that of its initial state. After $60 \mathrm{~s}$, a notably high number of graphene sheets had left the anode and spread into the electrolyte.

The exfoliated graphene sheets were then transferred onto a $\mathrm{Si} / \mathrm{SiO}_{2}$ substrate using the Langmuir-Blodgett method. The scanning electron microscopy (SEM) image displayed in Figure 2a provides unambiguous evidence for the uniform coverage of
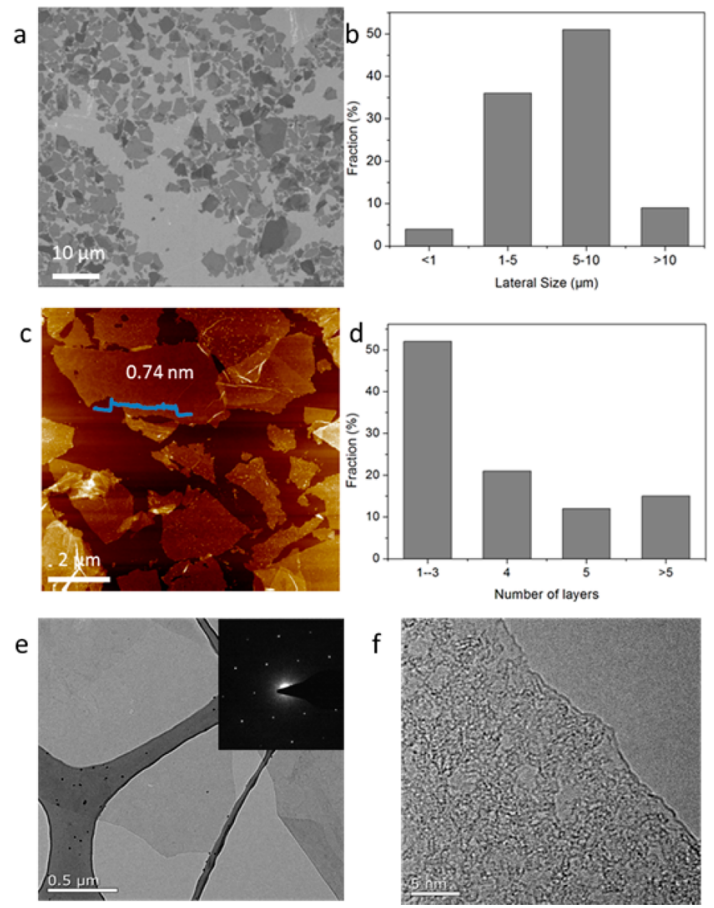

Figure 2. Morphology of exfoliated graphene: (a) SEM image of a large area of graphene on a $\mathrm{Si} / \mathrm{SiO}_{2}$ substrate, (b) statistical lateral size distribution determined by SEM, (c) AFM image of exfoliated graphene on $\mathrm{SiO}_{2}$, (d) statistical height profile analysis determined by AFM, (e) typical TEM image of a graphene sheet (inset, SAED pattern), (f) high-resolution TEM at the edge of a single-layer graphene sheet.

the $\mathrm{SiO}_{2}$ surface with assemblies of graphene sheets (hundreds of $\mu \mathrm{m}^{2}$ in size). The statistical analysis of 150 sheets revealed that the predominant lateral size distribution was between 5 and $10 \mu \mathrm{m}$ and that approximately $10 \%$ of the graphene sheets were larger than $10 \mu \mathrm{m}$ (Figure $2 \mathrm{~b}$ ). The number of layers per sheet was estimated using atomic force microscopy (AFM).
The thickness of the single-layer graphene sheets $(0.74 \mathrm{~nm})$ was in accordance with that of pristine graphene on a Si wafer (Figure $2 \mathrm{c}){ }^{25}$ Bilayer $(1.32 \mathrm{~nm})$ and trilayer $(2.01 \mathrm{~nm})$ sheets were also detected (Figure S4). A histogram of the thickness of 100 graphene sheets obtained by cross-sectional analysis displays that approximately $52 \%$ of the sampled graphene sheets are between one and three layers thick (23\% monolayers, 29\% bilayers, and trilayers) (Figure 2d). The decreased yield of 1-3 layered graphene is ascribed to the reaggregation of the sheets that occurs during the exfoliation process and/or sample preparation. Transmission electron microscopy (TEM) reveals that the graphene sheets typically feature some overlapping regions. This partial stacking results from the heating process that occurs during sample preparation, which is widely used to evaporate solvents. ${ }^{26}$ The selected-area electron diffraction (SAED) image at the central part of the graphene sheet identifies the high-quality crystalline structure evidenced by the typical 6-fold symmetric diffraction patterns (Figure 2e). ${ }^{27} \mathrm{~A}$ high-resolution TEM (HR-TEM) analysis of the flake edges reveals the well-defined structure of a singlelayer graphene sheet (Figure 2f).

Structural Investigation. As shown in Figure $3 \mathrm{a}$ and Figure S5a,b, a typical Raman spectrum (532 nm laser excitation) exhibits three main bands: one at $1353 \mathrm{~cm}^{-1}$ (D band), which is associated with the breathing mode of the $\mathrm{sp}^{3}$ carbon atoms; one at $1582 \mathrm{~cm}^{-1}$ (G band), which corresponds to the in-plane vibrations of the graphene lattice; and one at $2705 \mathrm{~cm}^{-1}$ (2D band), which is an overtone of the D band. ${ }^{8}$ It has been well accepted that the intensity ratio of the $\mathrm{D}$ band to the $\mathrm{G}$ band $\left(I_{\mathrm{D}} / I_{\mathrm{G}}\right)$ is associated with the content of defects. EG sheets that were prepared using ascorbic acid and sodium borohydride exhibited relatively low $I_{\mathrm{D}} / I_{\mathrm{G}}$ ratios $(0.23$ and 0.15 , respectively). Remarkably, using TEMPO, the EG sheets show only a slight bulge at the position of $\mathrm{D}$ band and exhibit an $I_{\mathrm{D}} /$ $I_{\mathrm{G}}$ ratio below 0.1 , which suggests that they have a very low defect density on the basal plane. Because edges act as "defects" during the Raman scattering process, the $I_{\mathrm{D}} / I_{\mathrm{G}}$ ratio at the edge $(0.17)$ is generally higher than that at the center of the plane. ${ }^{28}$ The relatively low intensity of the $2 \mathrm{D}$ band indicates that fewlayer graphene (2-4 layers) is present, which could be due to the reaggregation or folding of the samples during their preparation (this hypothesis could be confirmed by AFM characterization $)^{8}$

X-ray photoelectron spectroscopy (XPS) provided insight into the chemical composition of the exfoliated graphene (Figure $3 \mathrm{~b}$ and Figure S5c,d): only $6.6 \%$ and $8.4 \%$ atomic oxygen content was detected in EG samples prepared with sodium borohydride and ascorbic acid, respectively. Remark-
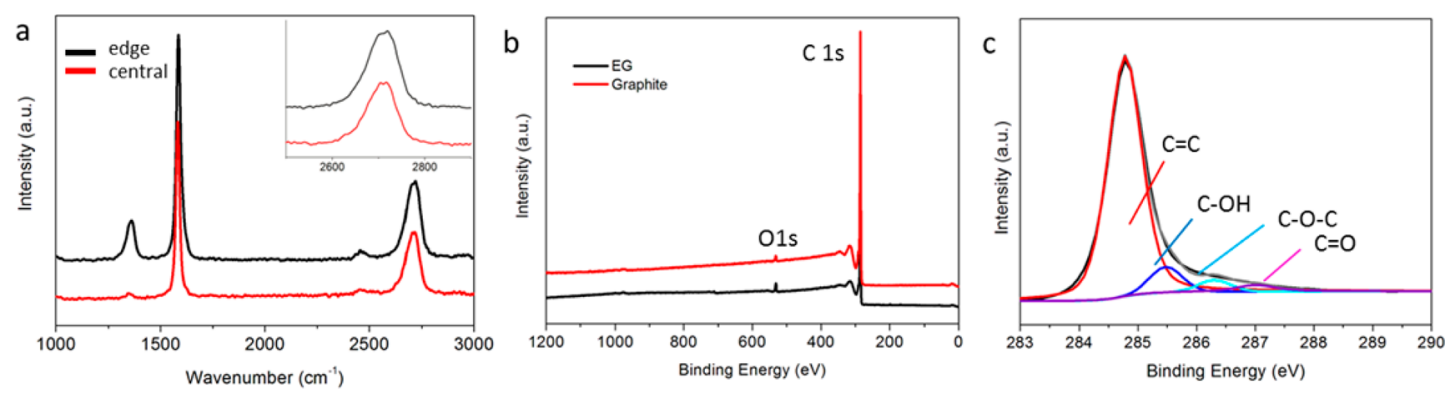

Figure 3. Structural characterization of exfoliated graphene: (a) representative Raman spectra from both the edge and the central plane of an EG sheet (532 nm laser excitation), (b) XPS survey spectra of graphite and EG, and (c) high-resolution C 1s spectrum measured on a thin EG film. 
ably, EG prepared using TEMPO exhibited the lowest oxygen content (as low as $3.8 \%$ ). This value is only slightly higher than that of the pristine graphite precursor $(1.7 \%)$. Thus, the $\mathrm{C} / \mathrm{O}$ ratio of the graphene sample is 25.3 , which is much greater than the $\mathrm{C} / \mathrm{O}$ ratios of the graphene samples prepared using other wet-chemical methods (Table S1, Supporting Information). According to the high-resolution spectrum of $\mathrm{C} 1 \mathrm{~s}$ (Figure 3c), a sharp peak located at a binding energy (BE) of $284.6 \mathrm{eV}$ corresponds to the $\mathrm{sp}^{2}$ carbons (graphitic $\mathrm{C}=\mathrm{C}$ species), ${ }^{29,30}$ and the other peaks at $285.4 \mathrm{eV}, 286.5$ and $287.2 \mathrm{eV}$ are assigned to the $\mathrm{sp}^{3}$ carbons $(\mathrm{C}-\mathrm{OH}),{ }^{31,32}$ and the oxygencarbon groups $(\mathrm{C}-\mathrm{O}-\mathrm{C}, \mathrm{C}=\mathrm{O}){ }^{32}$ respectively. Carboxylic groups $(\mathrm{O}-\mathrm{C}=\mathrm{O})$ were not detected at $290.2 \mathrm{eV} .^{19}$

Exfoliation Mechanism. In general, the efficient intercalation of electrolyte into graphite interlayer and the subsequent gas eruption are the key factors governing graphite exfoliation (Figure 4). The intercalation process preferentially
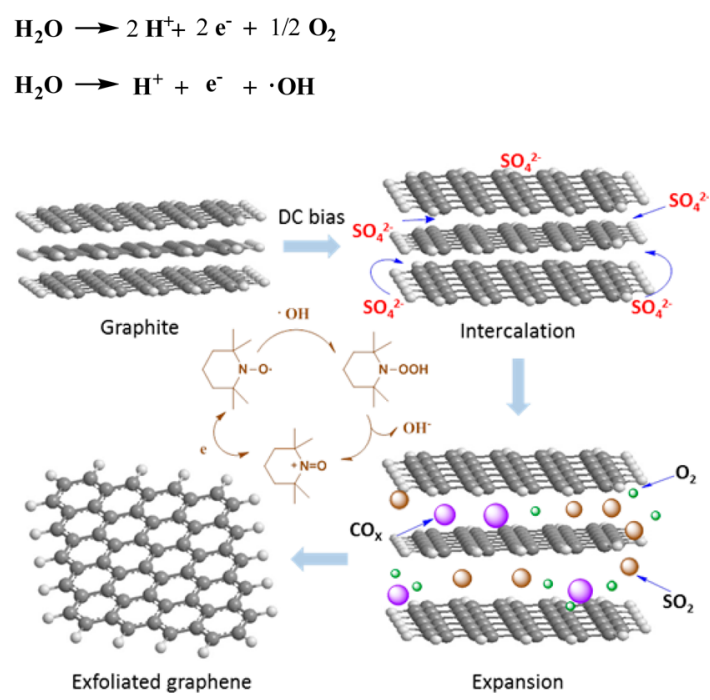

Figure 4. Mechanism of radical assisted electrochemical exfoliation. The exfoliation process includes two stages, intercalation and expansion. TEMPO acts as a radical-eliminating agent, defending against the attack of oxidative radicals; the intercalation of sulfate ions leads to complete exfoliation.

opens up the grain boundary, edge sites and other intrinsic defects where van der Waals interactions are weak, promoting gas evolution at the corresponding sites. Afterward, the large volume expansion on a microscopic scale enables efficient exfoliation. It is well-known that, in dilute or moderately concentrated salt solutions, water splitting takes place at a potential of $1.23 \mathrm{~V}$, generating oxygen gas at the anode. Nevertheless, the high anodic overpotential (e.g., $10 \mathrm{~V}$ ) discharges water into active intermediates, such as hydroxyl radicals, at the graphite interfaces. ${ }^{33}$

$$
\begin{aligned}
& \mathrm{H}_{2} \mathrm{O} \rightarrow 2 \mathrm{H}^{+}+2 \mathrm{e}^{-}+1 / 2 \mathrm{O}_{2} \\
& \mathrm{H}_{2} \mathrm{O} \rightarrow \mathrm{H}^{+}+\mathrm{e}^{-}+{ }^{\circ} \mathrm{OH}
\end{aligned}
$$

In the meantime, hydroxyl radicals $\left(\mathrm{HO}^{\bullet}\right)$ start to corrode the graphite electrode at the edges which is necessary to open the boundaries such that the sulfate ions are able to intercalate. However, these radicals are nonselective and highly active, and they cause the continuous oxidization of the graphite from the edges to the central plane. ${ }^{20,21,34}$ By using TEMPO, the extent of damage in graphene lattice, which is possibly caused by radical attack, could in principle be very low. Also, extensive graphite oxidation or structural disruption is not crucial for complete and fast exfoliation. The following exfoliation mechanism is proposed.

In the presence of the TEMPO radical, the reactive hydroxyl radical $\left(\mathrm{HO}^{\bullet}\right)$ will likely react immediately with the surrounding TEMPO radicals (nitroxides) to form metastable intermediates (e.g., TEMPO-OH), which are eventually converted to oxoammonium cations. ${ }^{35}$

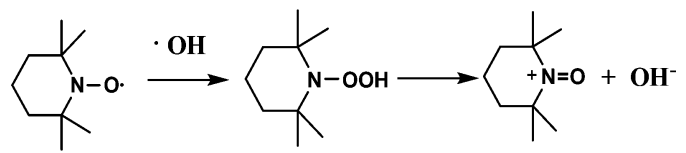

The oxoammonium cations will be electrochemically reduced at the cathode, forming pristine TEMPO radicals.<smiles>CC1(C)CCCC(C)(C)N1[O]</smiles>

UV-vis spectroscopy was carried out in order to monitor the stability of TEMPO under high potential. As shown in Figure S6, TEMPO exhibits distinctive UV absorbance maximum at $425 \mathrm{~nm}$. After $10 \mathrm{~min}$, the intensity of band decays slightly. When it comes to $60 \mathrm{~min}$, the concentration of TEMPO decreases dramatically owing to its electrochemical decomposition at air/water interfaces. ${ }^{36}$

The elimination of these radicals undoubtedly will prevent the graphite anode from excess-oxidation. Moreover, the high complexity of electrochemical reactions results in the violent evolution of various gaseous species (such as $\mathrm{CO}_{x}, \mathrm{SO}_{2}$, and $\left.\mathrm{O}_{2}\right){ }^{19}$ which will significantly weaken the van der Waals interactions and move the weakly bonded graphite layers apart.

To test this hypothesis, various filling amounts of TEMPO were investigated for graphite exfoliation (Figure S7). In all cases, the ammonium sulfate concentration was fixed at $0.1 \mathrm{M}$. The exfoliation efficiency of graphite gradually decreased with the increasing TEMPO concentration. When it ranged from 0.5 to $2 \mathrm{mg} \mathrm{mL}^{-1}$, the exfoliation yields did not change ( $\sim 70 \mathrm{wt}$ $\%)$. However, when the concentration of TEMPO was increased to $8 \mathrm{mg} \mathrm{mL}^{-1}$, the yield dropped to $\sim 45 \mathrm{wt} \%$. This result strongly confirms that oxidation at the boundaries (by radical attack) is crucial for the next step in the process (the intercalation of the sulfate ions). When most of the radicals are eliminated, the exfoliation yield is expected to be quite low.

Notably, we found that the addition of TEMPO decreased the defects present in the exfoliated graphene prepared using other aqueous electrolyte systems (Figure S8). For instance, with the use of TEMPO, the $I_{\mathrm{D}} / I_{\mathrm{G}}$ ratio of the exfoliated graphene dropped from 0.47 to 0.28 for potassium sulfate $\left(\mathrm{K}_{2} \mathrm{SO}_{4}\right)$ as aqueous electrolyte and from 0.58 to 0.32 for sodium sulfate $\left(\mathrm{Na}_{2} \mathrm{SO}_{4}\right)$. Thus, the effective control of the $I_{\mathrm{D}} /$ $I_{\mathrm{G}}$ ratio is consistent with the proposed radical-eliminating hypothesis.

Electrical Properties. The electrical properties of both single EG layers and continuous thin films (tens of nanometers thick) were evaluated using a field-effect transistor and sheet resistance measurements, respectively. Figure 5a shows the SEM images of an as-prepared device containing a graphene sheet in the channel. The mobility extracted from the transfer curves is $\sim 405 \mathrm{~cm}^{2} \mathrm{~V}^{-1} \mathrm{~s}^{-1}$, which is substantially greater than that of reduced graphene oxide $\left(123 \mathrm{~cm}^{2} \mathrm{~V}^{-1} \mathrm{~s}^{-1}\right)^{37}$ and electrochemically exfoliated graphene in sulfuric acid $\left(233 \mathrm{~cm}^{2}\right.$ 

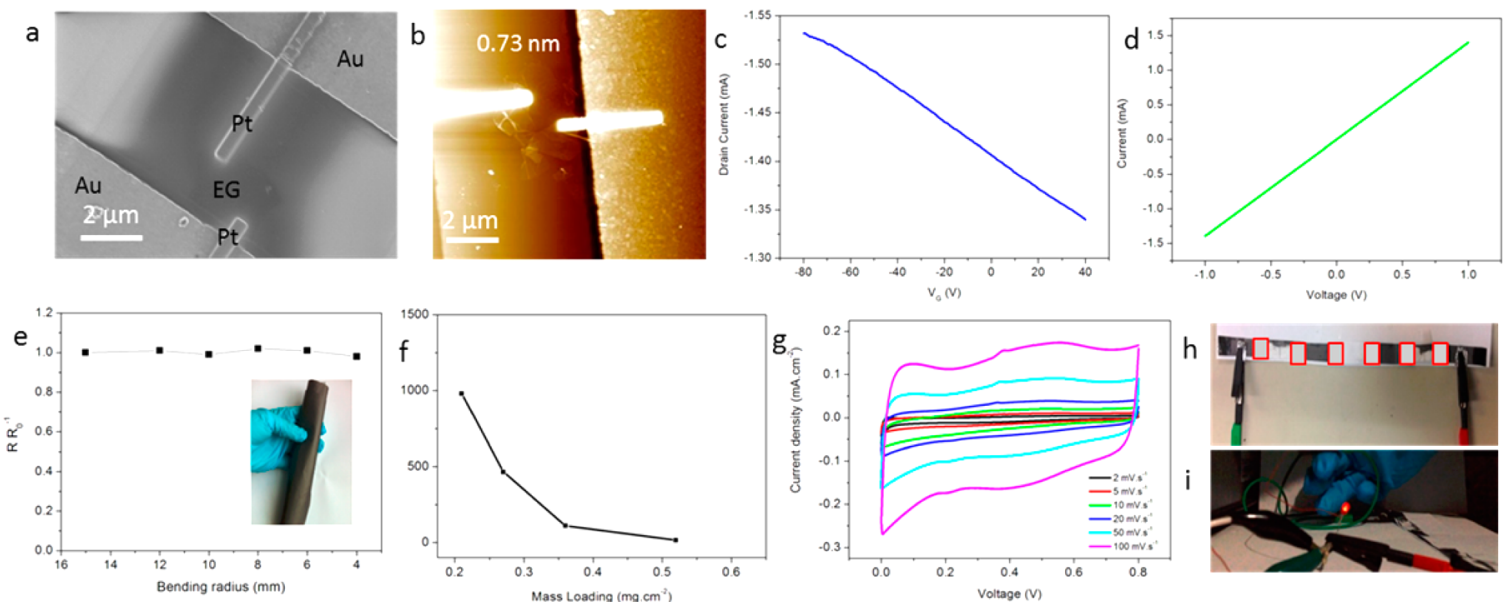

Figure 5. Electrical properties of EG. (a) SEM and (b) AFM images of an as-prepared FET device. (c) Transfer curve and (d) current-voltage (IV) curves of a FET device based on single-layer graphene. (e) The alternation of sheet resistance with the change of bending radius (inset, photograph of a rolled graphene paper). (f) Relationship between the resistance and graphene mass loading. (g) Cyclic voltammetry curves of the supercapacitors (graphene mass loading $0.52 \mathrm{mg} \mathrm{cm}^{-2}$ ) at scan rates between 2 and $100 \mathrm{mV} \mathrm{s}^{-1}$. (h,i) Photographs of the as-made connected supercapacitor and the moment when the LED lit up.

$\left.\mathrm{V}^{-1} \mathrm{~s}^{-1}\right)^{18}$ or ammonium sulfate aqueous solution $\left(310 \mathrm{~cm}^{2}\right.$ $\left.\mathrm{V}^{-1} \mathrm{~s}^{-1}\right)^{19}$ (detailed comparison is listed in Tables S2 and S3, Supporting Information). The sheet resistance (Rs), measured from the two-terminal $I-V$ traces, is $1.91 \mathrm{k} \Omega \mathrm{sq}^{-1}$. This value is comparable to some undoped CVD-grown graphene samples. ${ }^{38}$ Continuous graphene films were prepared by filtering a dilute graphene dispersion and then mechanically compressing it. The thickness of the films could be easily adjusted by tuning the volume and concentration of the starting dispersion. The transparency was monitored by UV spectroscopy at $550 \mathrm{~nm}$. Thin graphene films $(10 \mathrm{~nm})$ exhibited a transparency of $85 \%$, which is comparable to that of commercial ITO glass (90\% in the visible region) (Figure S9). ${ }^{39}$ The Rs was measured after the samples were annealed at a low temperature $\left(200{ }^{\circ} \mathrm{C}\right)$ overnight to remove any residual solvents. The average value recorded by a four-probe system was $9.47 \mathrm{k} \Omega \mathrm{sq}^{-1}$ and $3.91 \mathrm{k} \Omega$ $\mathrm{sq}^{-1}$ for films with a thickness of 10 and $20 \mathrm{~nm}$, respectively. Because nitric acid $\left(\mathrm{HNO}_{3}\right)$ is effective for $\mathrm{p}$-doping graphene films, ${ }^{40}$ after treatment with $\mathrm{HNO}_{3}(65 \%, 2 \mathrm{~h})$, the doped EG films displayed Rs values of 1.10 and $0.51 \mathrm{k} \Omega \mathrm{sq}^{-1}$, respectively, and maintained their optical transparency. The high transparencies of these conductive EG films compared well with those of graphene films that were made from the thermal intercalation-exfoliation approach or via the thermal reduction of graphene oxide. ${ }^{9,41}$ To explore the application of such highquality graphene in printable flexible electronics, a concentrated dispersion of EG in DMF $\left(6.0 \mathrm{mg} \mathrm{mL}^{-1}\right)$, as known as graphene ink, was freshly prepared and deposited on a commercial A4 paper by brush painting (Figure S10a). The resulting graphene paper (Figure $\mathrm{S} 10 \mathrm{~b}$ ) displayed outstanding flexibility because it could be bent arbitrarily without breaking (Figure 5e). A bending test of the graphene paper also demonstrated that the electrical conductivity remained nearly the same when the radius was reduced from 15 to $4 \mathrm{~mm}$. Moreover, the resistance of the graphene paper varied with different graphene loading. Figure $5 f$ shows that the resistance dropped from $980 \Omega \mathrm{sq}^{-1}$ to $15 \Omega \mathrm{sq}^{-1}$ with an increase of the EG mass loading from $0.21 \mathrm{mg} \mathrm{cm}{ }^{-2}$ to $0.52 \mathrm{mg} \mathrm{cm}^{-2}$, respectively. This superior conductivity at high loading is comparable to that of carbon nanotube paper. ${ }^{4{ }^{\circ}}$
In view of such controllable mass loading, the graphene paper holds great promise for the fabrication of flexible solidstate supercapacitors. In this case, the paper serves as a flexible substrate, and its porous structure allows for the diffusion of electrolyte ions, thus avoiding the use of any binders or additives. Toward this end, two graphene papers (mass loading: $0.52 \mathrm{mg} \mathrm{cm}$ ) were integrated together with a layer of solidified conductive gel (poly(vinyl alcohol)/sulfuric acid) to assemble an all-solid-state supercapacitor. In a cyclic voltammetry test, this flexible graphene paper-based supercapacitor showed typical double-layer capacitive behavior at various scan rates (Figure $5 \mathrm{~g}$ ). The calculated capacitance per geometric area was $11.5 \mathrm{mF} \mathrm{cm}{ }^{-2}$ (scan rate, $2 \mathrm{mV} \mathrm{s}^{-1}$ ), which is much higher than that of reduced graphene oxide ( $\mathrm{rGO}$ )cellulose paper supercapacitors $\left(7.6 \mathrm{mF} \mathrm{cm} \mathrm{cm}^{-2}\right){ }^{43}$ The residual oxygen-containing groups and defects on rGO are major barriers to high electrochemical performance. To examine the possible practical applications, six small paper supercapacitors (active area, $2 \mathrm{~cm}^{2} \times 6$ ) were connected in series (Figure S10C), and the assembled device had the capability to light up a red light-emitting diode (LED) at $2.5 \mathrm{~V}$, as shown in Figure 5h,i.

\section{CONCLUSION}

We have developed a controllable electrochemical approach for graphite exfoliation with the assistance of antioxidants. Among them, TEMPO was found to promote exfoliation, which led to graphene exhibiting superior quality in high yield. The exfoliated graphene sheets are large in size, and they have remarkably high hole mobilities $\left(\sim 405 \mathrm{~cm}^{2} \mathrm{~V}^{-1} \mathrm{~s}^{-1}\right)$ and high carbon to oxygen $(\mathrm{C} / \mathrm{O})$ ratios (25.3). The process used to prepare such graphene samples is superior to other wetchemical approaches. Moreover, the high solution-processability of graphene opens up ample opportunities for the fabrication of graphene-based thin film electrodes. Given that all of the reagents employed in this exfoliation system are commercially available and inexpensive and that the process is extremely fast, compatible to scale-up, and free of polluting byproducts, our method holds great promise to support the realization of an industrial graphene market. 


\section{ASSOCIATED CONTENT}

\section{S Supporting Information}

The Supporting Information is available free of charge on the ACS Publications website at DOI: 10.1021/jacs.5b09000.

Experimental details, chemical structure of reducing agents in this work, morphological changes of graphite during exfoliation process, additional AFM, Raman of exfoliated graphene, UV-vis spectra of electrolyte, comparison of wet-chemical methods for graphite exfoliation (PDF)

\section{AUTHOR INFORMATION}

\section{Corresponding Authors}

*xinliang.feng@tu-dresden.de

*muellen@mpip-mainz.mpg.de

\section{Notes}

The authors declare no competing financial interest.

\section{ACKNOWLEDGMENTS}

This work was financially supported by the ERC Grant on NANOGRAPH and 2DMATER, EC Marie Curie ITN Project GENIUS and IC- ICT FET-Proactive MoQuas, as well as the EC under Graphene Flagship (Grant No. CNECT-ICT604391), the FET Project UPGRADE (Project No. 309056), the ANR through the LabEx Project, BMBF INSOLCELL Project, and the International Center for Frontier Research in Chemistry (icFRC). The authors thank Dr. Ingo Lieberwirth for HR-TEM measurement. Sheng Yang would like to thank the China Scholarship Council (CSC) for financial support.

\section{REFERENCES}

(1) Gwon, H.; Kim, H.-S.; Lee, K. U.; Seo, D.-H.; Park, Y. C.; Lee, Y.S.; Ahn, B. T.; Kang, K. Energy Environ. Sci. 2011, 4, 1277.

(2) Novoselov, K. S.; Geim, A. K.; Morozov, S. V.; Jiang, D.; Zhang, Y.; Dubonos, S. V.; Grigorieva, I. V.; Firsov, A. A. Science 2004, 306, 666.

(3) León, V.; Rodriguez, A. M.; Prieto, P.; Prato, M.; Vázquez, E. ACS Nano 2014, 8, 563.

(4) Jeon, I.-Y.; Shin, Y.-R.; Sohn, G.-J.; Choi, H.-J.; Bae, S.-Y.; Mahmood, J.; Jung, S.-M.; Seo, J.-M.; Kim, M.-J.; Wook Chang, D.; Dai, L.; Baek, J.-B. Proc. Natl. Acad. Sci. U. S. A. 2012, 109, 5588.

(5) Hernandez, Y.; Nicolosi, V.; Lotya, M.; Blighe, F. M.; Sun, Z.; De, S.; McGovern, I. T.; Holland, B.; Byrne, M.; Gun'Ko, Y. K.; Boland, J. J.; Niraj, P.; Duesberg, G.; Krishnamurthy, S.; Goodhue, R.; Hutchison, J.; Scardaci, V.; Ferrari, A. C.; Coleman, J. N. Nat. Nanotechnol. 2008, 3, 563.

(6) Lotya, M.; Hernandez, Y.; King, P. J.; Smith, R. J.; Nicolosi, V.; Karlsson, L. S.; Blighe, F. M.; De, S.; Wang, Z.; McGovern, I. T.; Duesberg, G. S.; Coleman, J. N. J. Am. Chem. Soc. 2009, 131, 3611.

(7) Coleman, J. N. Acc. Chem. Res. 2013, 46, 14.

(8) Paton, K. R.; Varrla, E.; Backes, C.; Smith, R. J.; Khan, U.; O’Neill, A.; Boland, C.; Lotya, M.; Istrate, O. M.; King, P.; Higgins, T.; Barwich, S.; May, P.; Puczkarski, P.; Ahmed, I.; Moebius, M.; Pettersson, H.; Long, E.; Coelho, J.; O’Brien, S. E.; McGuire, E. K.; Sanchez, B. M.; Duesberg, G. S.; McEvoy, N.; Pennycook, T. J.; Downing, C.; Crossley, A.; Nicolosi, V.; Coleman, J. N. Nat. Mater. 2014, 13, 624 .

(9) Li, D.; Muller, M. B.; Gilje, S.; Kaner, R. B.; Wallace, G. G. Nat. Nanotechnol. 2008, 3, 101.

(10) Dreyer, D. R.; Park, S.; Bielawski, C. W.; Ruoff, R. S. Chem. Soc. Rev. 2010, 39, 228.

(11) Low, C. T. J.; Walsh, F. C.; Chakrabarti, M. H.; Hashim, M. A.; Hussain, M. A. Carbon 2013, 54, 1.
(12) Xia, Z. Y.; Giambastiani, G.; Christodoulou, C.; Nardi, M. V.; Koch, N.; Treossi, E.; Bellani, V.; Pezzini, S.; Corticelli, F.; Morandi, V.; Zanelli, A.; Palermo, V. ChemPlusChem 2014, 79, 439.

(13) Xia, Z. Y.; Pezzini, S.; Treossi, E.; Giambastiani, G.; Corticelli, F.; Morandi, V.; Zanelli, A.; Bellani, V.; Palermo, V. Adv. Funct. Mater. 2013, 23, 4756.

(14) Cooper, A. J.; Wilson, N. R.; Kinloch, I. A.; Dryfe, R. A. W. Carbon 2014, 66, 340.

(15) Wang, J.; Manga, K. K.; Bao, Q.; Loh, K. P. J. Am. Chem. Soc. 2011, 133, 8888.

(16) Zhong, Y. L.; Swager, T. M. J. Am. Chem. Soc. 2012, 134, 17896.

(17) Su, C.-Y.; Lu, A.-Y.; Xu, Y.; Chen, F.-R.; Khlobystov, A. N.; Li, L.-J. ACS Nano 2011, 5, 2332

(18) Parvez, K.; Li, R; Puniredd, S. R.; Hernandez, Y.; Hinkel, F.; Wang, S.; Feng, X.; Müllen, K. ACS Nano 2013, 7, 3598.

(19) Parvez, K.; Wu, Z.-S.; Li, R.; Liu, X.; Graf, R.; Feng, X.; Müllen, K. J. Am. Chem. Soc. 2014, 136, 6083.

(20) Wei, D.; Grande, L.; Chundi, V.; White, R.; Bower, C.; Andrew, P.; Ryhanen, T. Chem. Commun. 2012, 48, 1239.

(21) Lu, J.; Yang, J.-x.; Wang, J.; Lim, A.; Wang, S.; Loh, K. P. ACS Nano 2009, 3, 2367.

(22) Ohno, K.; Tsujii, Y.; Fukuda, T. Macromolecules 1997, 30, 2503.

(23) Zaremski, M. Y.; Plutalova, A. V.; Garina, E. S.; Lachinov, M. B.; Golubev, V. B. Macromolecules 1999, 32, 6359.

(24) Veregin, R. P. N.; Odell, P. G.; Michalak, L. M.; Georges, M. K. Macromolecules 1996, 29, 4161.

(25) Cheng, Z.; Zhou, Q.; Wang, C.; Li, Q.; Wang, C.; Fang, Y. Nano Lett. 2011, 11, 767 .

(26) Ciesielski, A.; Haar, S.; El Gemayel, M.; Yang, H.; Clough, J.; Melinte, G.; Gobbi, M.; Orgiu, E.; Nardi, M. V.; Ligorio, G.; Palermo, V.; Koch, N.; Ersen, O.; Casiraghi, C.; Samorì, P. Angew. Chem., Int. Ed. 2014, 53, 10355.

(27) Geng, D.; Wu, B.; Guo, Y.; Huang, L.; Xue, Y.; Chen, J.; Yu, G.; Jiang, L.; Hu, W.; Liu, Y. Proc. Natl. Acad. Sci. U. S. A. 2012, 109, 7992.

(28) Dresselhaus, M. S.; Jorio, A.; Hofmann, M.; Dresselhaus, G.; Saito, R. Nano Lett. 2010, 10, 751.

(29) Park, K. H.; Lee, D.; Kim, J.; Song, J.; Lee, Y. M.; Kim, H.-T.; Park, J.-K. Nano Lett. 2014, 14, 4306.

(30) Park, K. H.; Kim, B. H.; Song, S. H.; Kwon, J.; Kong, B. S.; Kang, K.; Jeon, S. Nano Lett. 2012, 12, 2871.

(31) Kovtyukhova, N. I.; Wang, Y.; Berkdemir, A.; Cruz-Silva, R.; Terrones, M.; Crespi, V. H.; Mallouk, T. E. Nat. Chem. 2014, 6, 957.

(32) Zhang, L.; Zhang, Z.; He, C.; Dai, L.; Liu, J.; Wang, L. ACS Nano 2014, 8, 6663.

(33) Bergmann, M. E. H.; Rollin, J. Catal. Today 2007, 124, 198.

(34) Rao, K. S.; Sentilnathan, J.; Cho, H.-W.; Wu, J.-J.; Yoshimura, M. Adv. Funct. Mater. 2015, 25, 298.

(35) Samuni, A.; Goldstein, S.; Russo, A.; Mitchell, J. B.; Krishna, M. C.; Neta, P. J. Am. Chem. Soc. 2002, 124, 8719.

(36) Glandut, N.; Malec, A. D.; Mirkin, M. V.; Majda, M. J. Phys. Chem. B 2006, 110, 6101.

(37) Feng, H.; Cheng, R.; Zhao, X.; Duan, X.; Li, J. Nat. Commun. 2013, 4, 1539.

(38) Kholmanov, I. N.; Magnuson, C. W.; Aliev, A. E.; Li, H.; Zhang, B.; Suk, J. W.; Zhang, L. L.; Peng, E.; Mousavi, S. H.; Khanikaev, A. B.; Piner, R.; Shvets, G.; Ruoff, R. S. Nano Lett. 2012, 12, 5679.

(39) You, Y. Z.; Kim, Y. S.; Choi, D. H.; Jang, H. S.; Lee, J. H.; Kim, D. Mater. Chem. Phys. 2008, 107, 444.

(40) Bae, S.; Kim, H.; Lee, Y.; Xu, X.; Park, J.-S.; Zheng, Y.; Balakrishnan, J.; Lei, T.; Ri Kim, H.; Song, Y. I.; Kim, Y.-J.; Kim, K. S.; Ozyilmaz, B.; Ahn, J.-H.; Hong, B. H.; Iijima, S. Nat. Nanotechnol. 2010, 5, 574

(41) Li, X.; Zhang, G.; Bai, X.; Sun, X.; Wang, X.; Wang, E.; Dai, H. Nat. Nanotechnol. 2008, 3, 538.

(42) Hu, L.; Choi, J. W.; Yang, Y.; Jeong, S.; La Mantia, F.; Cui, L.-F.; Cui, Y. Proc. Natl. Acad. Sci. U. S. A. 2009, 106, 21490.

(43) Weng, Z.; Su, Y.; Wang, D.-W.; Li, F.; Du, J.; Cheng, H.-M. Adv. Energy Mater. 2011, 1, 917. 